\title{
PENGGUNAAN DATA MIKROTREMOR DAN Vs30 UNTUK MENGETAHUI HUBUNGAN KETEBALAN SEDIMEN TERHADAP PRODUKTIVITAS KELAPA SAWIT DAN IMPLEMENTASINYA DALAM PEMBELAJARAN FISIKA
}

\section{(Use of Microtremor and Vs30 Data to Know the Sediment Relation Towards the Palm Oil Productivity and Implementation in Physical Learning)}

\author{
Riska Marwanti ${ }^{1}$, L. Firdaus ${ }^{2}$, M. Farid ${ }^{3}$ \\ ${ }^{1}$ Mahasiswa Pascasarjana Pendidikan IPA, Universitas Bengkulu \\ ${ }^{2}$ Dosen Pascasarjana Pendidikan IPA, Universitas Bengkulu \\ ${ }^{3}$ Dosen Jurusan Fisika FMIPA Universitas. Bengkulu \\ rizkamarwanti@gmail.com
}

\begin{abstract}
The aims of this study were to determine the relationship of sediment thickness to palm oil productivity and to know the improvement of student learning outcomes after learning using LKPD based on service learning. This study was conducted using HVSR (Horizontal to Vertical Spectral Ratio) method. Data were collected as 10 primary data points, while secondary data on palm oil productivity was obtained from PT Bio Nusantara Teknologi. Data obtained from field measurements are numerical data of natural wave recording or seismic signal at each measurement point. The data is processed using Geopsy software so it can be known the price of the dominant frequency (fo), while the shear wave velocity (Vs30) is obtained through USGS data. The result of this research is there is intermediate relationship between sediment thickness to productivity of palm oil with product moment correlation value equal to 0,6392 , so that thicker layer of sediment hence higher productivity. The results of this study further used as a source of information contained in the form of LKPD-based service learning to become a learning medium taught by Problem Based Learning (PBL) model on students of class XI SMK N 1 Padang Jaya to know the improvement of students' cognitive learning outcomes in physics learning. The result of research implementation influence of sediment thickness to productivity of palm oil in classroom study showed cognitive learning result of learners experience improvement of cognitive learning result with average value of $\mathrm{N}$-gain of 0,52 (medium criterion).
\end{abstract}

Keywords: HVSR Method, Vs30, Sediment Thickness, Productivity, Oil Palm, LKPD Based Service Learning

\footnotetext{
ABSTRAK

Penelitian ini bertujuan untuk mengetahui hubungan ketebalan sedimen terhadap produktivitas kelapa sawit dan mengetahui peningkatan hasil belajar siswa setelah dilakukan pembelajaran menggunakan LKPD berbasis service learning. Penelitian ini dilakukan dengan menggunakan metode HVSR (Horizontal to Vertical Spectral Ratio). Pengambilan data dilakukan sebanyak 10 titik yang merupakan data primer, sedangkan data sekunder mengenai produktivitas kelapa sawit didapatkan dari PT Bio Nusantara Teknologi. Data yang didapatkan dari pengukuran di lapangan berupa data numerik rekaman
} 
gelombang natural atau signal seismik di setiap titik pengukuran. Data tersebut diolah menggunakan software Geopsy sehingga dapat diketahui harga frekuensi dominan (fo), sedangkan kecepatan gelombang geser (Vs30) didapatkan melalui data USGS. Hasil penelitian ini adalah terdapat hubungan sedang antara ketebalan sedimen terhadap produktivitas kelapa sawit dengan harga korelasi product moment sebesar 0,6392, sehingga semakin tebal lapisan sedimen maka produktivitas semakin tinggi. Hasil penelitian ini selanjutnya dijadikan sumber informasi yang dimuat dalam bentuk LKPD berbasis service learning sehingga menjadi media pembelajaran yang diajarkan dengan model Problem Based Learning ( $P B L$ ) pada siswa kelas XI SMK N 1 Padang Jaya untuk mengetahui peningkatan hasil belajar kognitif siswa dalam pembelajaran fisika. Hasil dari implementasi penelitian pengaruh ketebalan sedimen terhadap produktivitas kelapa sawit pada pembelajaran di kelas menunjukkan hasil belajar kognitif peserta didik mengalami peningkatan hasil belajar kognitif dengan nilai rata-rata $\mathrm{N}$-gain sebesar 0,52 (kriteria sedang).

Kata Kunci: Metode HVSR, Vs30, Ketebalan Sedimen, Produktivitas, Kelapa Sawit, LKPD Berbasis Service Learning

\section{PENDAHULUAN}

Indonesia memiliki kapasitas produksi minyak sawit yang mengungguli produsen dari negara lainnya (Rachmawati et al, 2010). Jumlah produksi minyak kelapa sawit di Indonesia pada tahun 2015 mencapai 31,10 juta ton. Menurut Direktorat Jenderal Perkebunan, Indonesia memiliki sumber daya lahan yang sangat luas untuk pengembangan berbagai komoditas pertanian.

Setiap tanaman akan hidup normal tergantung dengan kondisi lahan yang sesuai dengan kebutuhan tanaman tersebut. Tanaman kelapa sawit selama ini diketahui dapat hidup pada ketinggian $0-500 \mathrm{~m}$ dpl, akan tetapi belum diketahui pada ketebalan berapa meter tanaman kelapa sawit dapat tumbuh secara optimal.

Gandasasmita et. al (2009), Wigena et. al (2009), Pamuji, et. al (2015), maupun Martasari (2013) semua menghubungkan antara jenis dan lapisan tanah, akan tetatapi lebih dominan ke arah kimia tanah dan jenis tanah dalam setiap lapisan. Penelitian ini lebih menguatkan para peneliti di atas yaitu menghubungkan ketebalan sedimen dengan produktivitas buah. Peneltian ini tergolong baru karena ketebalan sedimen lebih ke arah fisik, sementara produktivitas lebih ke ekonomis.

Pipkin (1977) menyatakan bahwa sedimen adalah pecahan, mineral, atau material organik yang ditransforkan dari berbagai sumber dan diendapkan oleh media udara, angin, es, atau oleh air. Dari sisi fisika, ketebalan sedimen dapat dihubungkan dengan frekuensi resonansi getaran tanah dan kecepatan gelombang geser $\left(\bar{v}_{s}\right)$. Pramuji (2005) mengemukakan bahwa jika batuan dasar semakin dalam, maka semakin kecil frekuensi resonansinya, sebaliknya semakin dangkal batuan dasar, maka akan memiliki frekuensi resonansi yang semakin tinggi. Hubungan antara frekuensi resonansi dengan ketebalan sedimen dapat dicari dengan menggunakan kaidah pipa organa sebagai berikut :

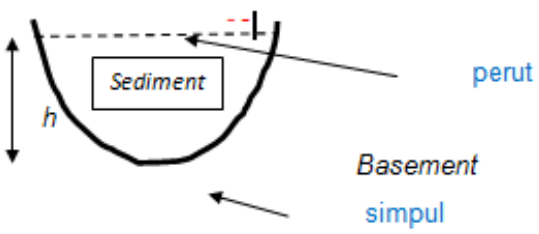


Gambar 1. Sedimen dan basement disamakan dengan pipa organa

$$
\begin{aligned}
& \text { pada kondisi } \frac{1}{4} \lambda \\
& \quad h=\frac{1}{4} \lambda, f_{o}=\frac{\square}{\square} \text { diperoleh, } \\
& f_{o}=\square_{\square} v / 4 h \quad(2-1)
\end{aligned}
$$

Grafik hubungan antara frekuensi resonansi dengan kedalaman batuan dasar yang membentuk hubungan hiperbolik merupakan salah satu indikasi yang menggambarkan reliabilitas peralatan survei yang digunakan. Berdasarkan hubungan antara tebal sedimen dengan frekuensi resonansi, persamaan kecepatan rata-rata gelombang-S adalah:

$$
=4 \mathrm{~h}
$$

dengan $\quad \bar{\square}_{\square}$ adalah kecepatan ratarata gelombang-S, $h$ adalah tebal lapisan sedimen, dan $f_{o}$ adalah frekuensi resonansi (Bonnefoy, 2004). Hasil $\bar{\square}$ ini tentu saja estimasi perhitungan kasar berdasarkan frekuensi resonansi terkait dengan tebal lapisan sedimen. terdapat kecenderungan semakin tebal sedimen akan memiliki $\bar{\square}_{\square}$ yang lebih besar. Dalam penelitian ini Vs30 digunakan untuk menentukan nilai ketebalan sedimen dengan menggunakan formulasi (2-2). Adapun frekuensi yang digunakan adalah frekuensi resonansi hasil olah data mikrotremor di daerah yang diteliti, seperti ditunjukkan pada Gambar 2.

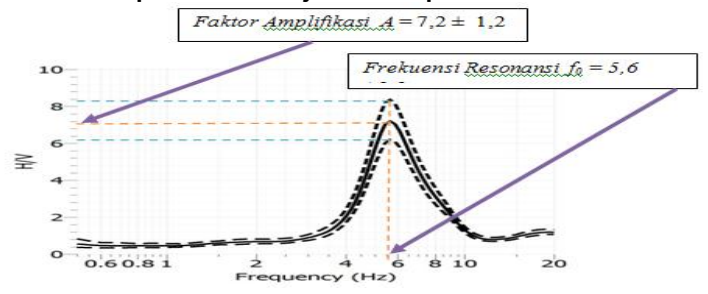

Gambar 2. Contoh spketrum hasil olah data peneltian diperoleh frekuensi resonansi dan faktor amplifikasi

Hasil penelitian berupa data ketebalan sedimen yang akan dihubungkan oleh produktivitas kelapa sawit di afdeling 1 PT Bio Nusantara Teknologi. Tabel 01. merupakan produktivitas kelapa sawit di lima blok afdeling 1 yang menjadi titik pengambilan data.
Tabel 01. Produktivitas kelapa sawit

\begin{tabular}{|c|c|c|c|c|}
\hline \multirow{2}{*}{ Blok } & \multicolumn{3}{|c|}{$\begin{array}{c}\text { Jumlah Produksi } \\
\mathbf{( k g ) / h a}\end{array}$} & \multirow{2}{*}{ Total } \\
\cline { 2 - 4 } & $\mathbf{2 0 1 4}$ & $\mathbf{2 0 1 5}$ & $\mathbf{2 0 1 6}$ & \\
\hline 4 & 17.9 & 15.76 & 13.65 & 47.73 \\
\hline 5 & 19.3 & 20.90 & 19.52 & 59.75 \\
\hline 13 & 17.3 & 12.95 & 12.51 & 42.72 \\
\hline 15 & 16.4 & 15.06 & 14.60 & 46.04 \\
\hline 18 & 14.4 & 18.58 & 27.12 & 60.11 \\
\hline
\end{tabular}

Selanjutnya hasil penelitian ketebalan sedimen yang telah dihubungkan dengan produktivitas kelapa sawit akan dijadikan sumber informasi yang dimuat dalam bentuk Lembar Kerja Peserta Didik (LKPD) berbasis Service Learning yang akan diajarkan dengan model pembelajaran Problem Based Learning.

Maurice (2010), service learning merupakan cara mengajar dan belajar yang menghubungkan tindakan positif dan bermakna di masyarakat dengan pembelajaran akademik, perkembangan pribadi dan tanggung jawab sebagai warga masyarakat.

LKPD berbasis service learning adalah LKPD yang disusun berdasarkan tujuan yang dapat dicapai oleh model pembelajaran service learning. Service Learning atau Experiential learning diperkenalkan John Dewey sebagai model pembelajaran lapangan. Tujuan model pembelajaran service learning ini selain melatih siswa agar memiliki pengetahuan tentang situasi nyata dalam masyarakat dan kemampuan untuk mengatasinya, serta untuk membentuk karakter terutama agar mereka memiliki kesadaran berbela rasa atau peduli terhadap kaum yang lemah dan tersisihkan (preferential option for the poor). Tahapan model service learning akan dimuat dalam penyusunan LKPD yang akan diajarkan kepada siswa dengan model pembelajaran problem based learning.

Model problem based learning (PBL) tepat untuk digunakan mengingat $P B L$ dapat membantu peserta didik mengembangkan kemampuan berfikir, pemecahan masalah, keterampilan intelektual, belajar berbagai berperan 
orang dewasa melalui pelibatan mereka dalam pengalaman nyata sehingga menjadi pembelajar yang otonom dan mandiri (Trianto, 2010).

\section{METODE}

\section{Lokasi Penelitian}

Penelitian dilakukan di afdeling 1 PT Bio Nusantara Teknologi Kecamatan Pondok Kelapa, Bengkulu Tengah. Wilayah ini terletak pada koordinat $-3,4--3,5$ LS dan 102,6 - 102,7 BT.

Implementasi hasil penelitian ketebalan sedimen diajarkan di SMK $\mathrm{N} 1$ Padang Jaya pada kelas XI jurusan Agribisnis Tanaman Perkebunan.

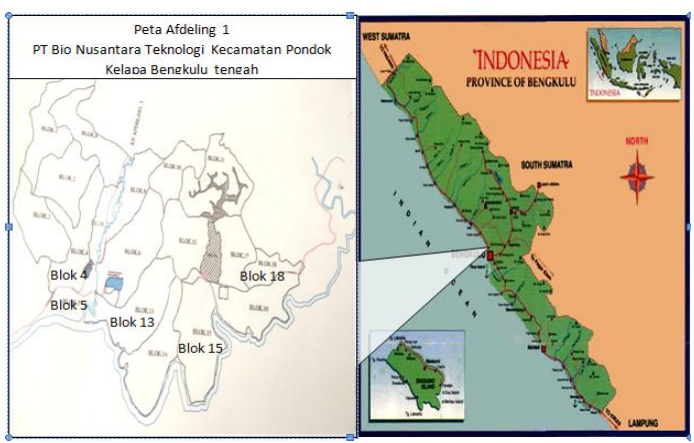

\section{Desain Penelitian \\ Waktu Penelitian}

Pengambilan data produktivitas kelapa sawit di afdeling satu dilakukan dari tanggal 4 April hingga 13 April 2017. Sedangkan Penelitian pengukuran ketebalan sedimen dilakukan pada tanggal 6 Juni 2017.

\section{Menentukan titik}

Penelitian dilakukan pada 5 blok di afdeling 1 PT. Bio Nusantara Teknologi. Blok yang menjadi titik pengambilan data adalah blok 4, 5, 13, 15, dan 18. Pemilihan kelima blok didasarkan pada akses untuk mencapai lokasi, dan kondisi lokasi yang dapat dilakukan penelitian dimana alat ini tidak dapat bekerja pada lokasi yang tergenang air.

Desain penelitian pendidikan

Untuk mengetahui peningkatan pengetahuan peserta didik, maka hasil belajar kognitif diambil dari nilai evaluasi sebelum dan setelah pembelajaran dengan pretest dan posttest

\section{Pengolahan Data}

Setelah dilakukan penelitian di lapangan, didapatkan hasil rekam data mikrotremor yang selanjutnya diolah menggunakan aplikasi geopsy untuk mendapakan harga $f_{0}$ dan $A_{0}$. Pengolahan data menggunakan software Geopsy akan diperoleh grafik HVSR, sehingga akan didapatkan nilai frekuensi dan amplitudo dari masing-masing puncak HVSR.

Ketebalan sedimen dapat dihitung setelah didapatkan harga $\mathrm{f}_{0}$, dan Vs30. Frekuensi dominan $\left(f_{o}\right)$ didapat melalui software geopsy, sedangkan untuk mendapatkan data Vs30 didapatkan melalui situs USGS.

Ketebalan sedimen dapat diketahui menggunakan rumus Nakamura setelah data $f_{0}$ dan Vs30 diketahui. Rumus Nakamura yang digunakan yaitu $: h=\frac{\square 30}{4 \square \square}$.

\section{HASIL DAN PEMBAHASAN}

Data hasil produktivitas kelapa sawit dan perhitungan ketebalan sedimen ditampilkan dengan diagram di bawah ini:

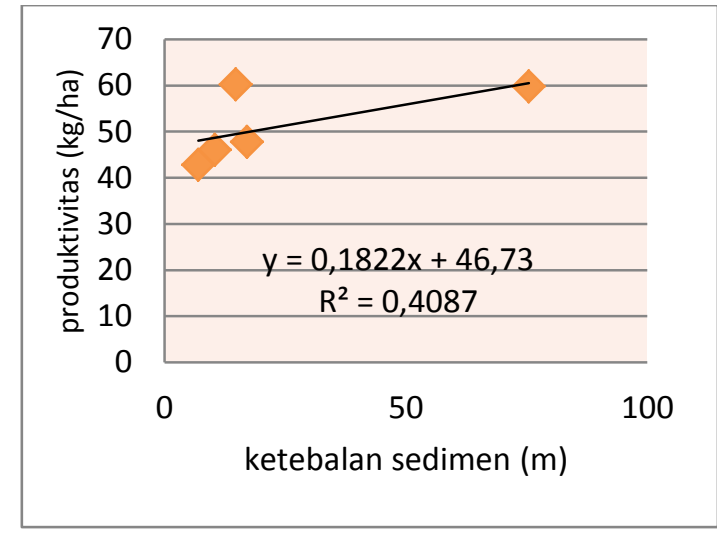

Gambar 4. hubungan ketebalan lapisan sedimen dan produktivitas kelapa sawit

Untuk menguji ada atau tidaknya hubungan antara ketebalan sedimen dengan produktivitas kelapa sawit, maka dilakukan uji pearson product moment menghasilkan data sebagai berikut : 
Tabel 02. Tabel Korelasi Ketebalan

Sedimen dengan Produktivitas

\begin{tabular}{|c|c|c|}
\hline $\begin{array}{c}\text { Ketebalan } \\
(\mathrm{m})\end{array}$ & $\begin{array}{c}\text { Produkivitas } \\
\text { (kg/ha) }\end{array}$ & korelasi \\
\hline 17,1 & \multirow{2}{*}{47,73} & \multirow{10}{*}{0,6392} \\
\hline 70,8 & & \\
\hline 75,5 & \multirow{2}{*}{59,7} & \\
\hline 45,2 & & \\
\hline 7,0 & \multirow{2}{*}{42,72} & \\
\hline 14,5 & & \\
\hline 10,5 & \multirow{2}{*}{46,04} & \\
\hline 61,9 & & \\
\hline 14,8 & \multirow{2}{*}{60,2} & \\
\hline 19,3 & & \\
\hline
\end{tabular}

Berdasarkan tabel di atas, dapat kita ketahui bahwa skor korelasi hubungan antara ketebalan sedimen dan produktivitas kelapa sawit adalah 0,6392. Artinya, sesuai dengan pedoman umum dalam menentukan korelasi, ada hubungan korelasi sedang antara ketebalan sedimen dan produktivitas kelapa sawit, yaitu semakin tebal lapisan sedimen maka produktivitas kelapa sawit semakin tinggi.

Setelah hubungan antara ketebalan lapisan sedimen dan produktivitas diketahui, selanjutnya data tersebut ditampilkan dalam LKPD berbasis service learning dan diajarkan kepada peserta didik. Sebelum pembelajaran siswa diberikan tes, setelah pembelajaran, siswa kembali mengerjakan soal tes yang sama.

Peningkatan hasil belajar kognitif setelah diajarkan dengan media LKPD berbasis service Learning menggunakan model pembelajaran $P B L$ dapat dilihat pada gambar 5 .

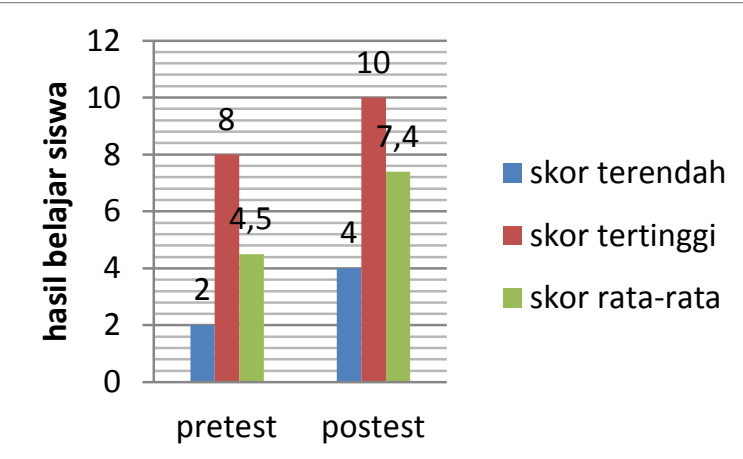

Gambar 5. Grafik Perbandingan hasil pretest dan posttest

Berdasarkan grafik di atas, dapat kita lihat bahwa skor posttest siswa dari skor tertinggi, terendah, serta skor rata-rata mengalami peningkatan. Hal ini membuktikan bahwa setelah dilakukan perlakuan yaitu pembelajaran di kelas menggunakan LKPD berbasis service learning dengan model Problem Based Learning dapat menaikkan hasil belajar fisika siswa, senada dengan pendapat Wibawa (2015) dalam penelitiannya, bahwa Problem Based Learning dapat meningkatkan hasil belajar, motivasi, dan aktivitas siswa di dalam kelas, sejalan pula dengan penelitian Rahmat, et al (2017) dalam penelitiannya tentang pengembangan LKPD IPA berbasis service learning materi sistem pencernaan untuk meningkatkan reflective thinking peserta didik SMPN 1 Mlati menyimpulkan bahwa berdasarkan perhitungan didapat rata-rata nilai pretest yaitu sebesar 72,19 dan ratarata nilai posttest yaitu 90,63. Hasil skor pretest dan posttest siswa setelah dihitung dengan $\mathrm{N}_{\text {gain }}$ menghasilkan tiga klasifikas di sebagai berikut :

Tabel 4.3 Presentase Klasifikasi kenaikan hasil belajar siswa berdasarkan Skor $N_{\text {Gain }}$ tiap siswa

\begin{tabular}{|l|r|r|}
\hline Klasifikasi & Jumlah siswa & Presentase \\
\hline Tinggi & 2 & $11 \%$ \\
\hline Sedang & 13 & $72 \%$ \\
\hline Rendah & 3 & $17 \%$ \\
\hline
\end{tabular}

Dari tabel 4.3 diketahui bahwa berdasarkan skor $\mathrm{N}_{\text {gain }}$ dapat diklasifikasikan menjadi 3 kriteria, yaitu tinggi, sedang, dan rendah. Siswa dominan berada pada kategori sedang dengan presentase $72 \%$. Berdasarkan perhitungan didapat rata-rata nilai pretest dalam satu kelas yaitu sebesar 4,5 dan rata-rata nilai posttest sebesar 7,4 . Sehingga dapat dihitung $\mathrm{N}_{\text {gain }}$ kelompok sebesar 0,52 yang berada pada kategori "sedang".

\section{PENUTUP \\ SIMPULAN}

Berdasarkan penelitian yang telah dilakukan, dapat disimpulkan bahwa: 
1. Terdapat hubungan antara ketebalan sedimen dengan produktivitas kelapa sawit, ditunjukkan dengan koefisien relasi pada diagram scatter menunjukkan angka 0,408 yang mendekati +1 menunjukkan terdapatnya hubungan, selain itu berdasarkan Uji hipotesis menggunakan Product Moment , koefisien korelasi menunjukkan angka 0,6392 yang berarti ada hubungan sedang antara ketebalan sedimen dan produktivitas kelapa sawit.

2. Adanya peningkatan skor hasil belajar kognitif peserta didik setelah diajarkan menggunakan LKPD berbasis service learning dengan model pembelajaran Problem Based Learning berdasarkan nilai rata-rata $\mathrm{N}$-gain kelompok 0,52 (kriteria sedang)

\section{SARAN}

Saran-saran yang peneliti dapat berikan antara lain:

1. Titik pengambilan data sebaiknya lebih banyak, sehingga hasil penelitian akan lebih jelas dan tegas.

2. Penelitian sejenis dapat dilakukan dengan menghubungkan pengaruhnya terhadap variabel yang lain.

\section{DAFTAR PUSTAKA}

Bonnefoy, S.C., Cotton, F., dan Bard, P.-Y. 2006. The Nature of Noise Wavefield and its Applications for Site Effects Studies: A Literature Review. EarthScience Reviews, 79(3-4), 205227.

Gandasasmita, K., Sumawinata, B., Nurmala, S..2009. Hubungan Karakteristik Lahan Dengan Produktivitas TBS. Jurnal Tanah dan Lingkungan : Institut Pertanian Bogor

Martasari, S.F. 2013. Analisis Struktur Lapisan Tanah Berdasarkan Ketebalan Sedimen Menggunakan Mikrotremor Dengan Metode Horizontal to Vertical Spektral Ratio (HVSR). Skripsi Fakultas Sains dan Teknologi : Universitas Islam Negeri Sunan Kalijaga

Maurice. 2010. Service Learning Handbook. North Carolina: Guilford County Schools, Service Learning Handbook.pdf
Pamuji, A., Muskananfola, M.R., A'in, C. 2015. Pengaruh Sedimentasi terhadap Kelimpahan Makrozoobenthos di Muara Sungai Betahwalang Kabupaten Demak. Jurnal Saintek Perikanan : Universitas Diponegoro

Pipkin, B.W. 1977. Laboratory Exercise in Oceanography. San Fransisco : W.H. Freeman and Company.

Pramuji, Bram .2015. Pengolahan Data Site Effect Di Kabupaten Bantul Berdasarkan Pengukuran Mikrotremor Dengan Studi Kasus Gempa Yogyakarta 27 Mei 2006. Masters thesis, upn "veteran" yogyakarta.

Rachmawati, Buchori, D., Hidayat, P., Hem, S., Fahmi, M.R. 2010. Perkembangan dan Kandungan Nutrisi Larva Hermetia illucens (Linnaeus) (Diptera: Stratiomyidae) pada Bungkil Kelapa Sawit. Institut Pertanian Bogor

Trianto. 2010. Mendesain Model Pembelajaran Inovatif - Progresif. Surabaya : Kencana

Rahmat, Yudist P, Asri W, Widodo SW. 2017. Pengembangan LKPD IPA Berbasis Service Learning Materi Sistem Pencernaan untuk Meningkatkan Reflective Thinking Peserta Didik SMPN 1 Mlati. Jurnal FMIPA Universitas Negeri Yogyakarta.

Wibawa. 2015. Penerapan Metode Pembelajaran Problem Based Learning untuk Meningkatkan Motivasi dan Prestasi Belajar Siswa Kelas XI pada Mata Pelajaran Menggambar Teknik Mesin di SMK PIRI Sleman. Skripsi. Fakultas Teknik UNY.

Wigena, I.G.P., Sudrajat, Sitorus, S.R.P., Siregar, H. 2009. Karakterisasi Tanah dan Iklim serta kesesuaiannya untuk Kebun Kelapa Sawit Plasma di Sei Pagar, Kabupaten Kampar, Provinsi Riau. Jurnal Tanah dan Iklim. Jakarta: Pusat Perbukuan, Departemen Pendidikan Nasional. 
